\title{
Wind Electricity Generation in Three States of India: Policies and Status
}

\author{
Sridhar Thyageswaran \\ Coimbatore Institute of Technology, Coimbatore-641014, India \\ *corresponding author: E-mail: t.sridhar@cit.edu.in
}

\begin{abstract}
Many state governments in India rely on wind energy generation (WEG) to overcome chronic electricity shortages. This paper provides a citizen's view of WEG in India, in the backdrop of (a) the everrising national demand for primary energy, (b) the national electricity policy, and (c) wind energy policies in its three highly industrialized states - Tamil Nadu, Maharashtra, and Gujarat. Data from public domain such as the web-sites of government departments is used. Each state has increased its share of WEG with incentives for investment in this sector. The remarkable increase in installed capacity for WEG over the past years has not led to a proportionate increase in the kWh of wind power generated. The unbridled growth in this sector has pitted farmer activists against wind energy companies. A stampede for commissioning large wind farms can potentially destroy local ecosystems through changes in land use patterns. Few studies have been made in India to address such socio-economic concerns. Policies of doling out excessive incentives for MW-scale underutilized wind farms that feed inefficient grids must be reconsidered. The people of India must receive direct tangible benefits from WEG for it to be a truly clean option of green energy for them.
\end{abstract}

Keywords: Government, Policy, Status, Capacity, Utilization

\section{Introduction}

Energy-starved India faces many challenges to sustain the remarkable growth in its GDP witnessed over the past decade. The consumption of manufactured products and services has sharply increased with a rise in disposable incomes, and its people expect better living conditions. Ambitious projects are underway to upgrade the nation's infrastructure, to transform India into another economic superpower. To meet these expectations, India's electricity generation capacity must be significantly increased from its current gross value of 164.8 GW [1]. Demand for primary commercial energy, which grew at an average annual rate of $6 \%$ during 1981-2001, is expected to grow more rapidly in the future [2].

\subsection{Background}

Energy policies world-wide are giving an increasing importance to clean sources of energy. A UN-panel has recommended an 85\% cut in global greenhouse gas emissions (GHGE) from year-2000 levels to prevent the ill-effects of global warming. India currently produces about $1 / 4^{\text {th }}$ of the world's annual per capita emissions of $4.48 \mathrm{t} \cdot \mathrm{CO}_{2} \mathrm{e}$ (tonnes of $\mathrm{CO}_{2}$ equivalent). During the last G-8 Summit, India agreed to work with other major economies in identifying a global goal for reducing GHGE [3]. Critics opine that India has compromised its policy of rejecting legally binding limits on its GHGE, and any caps would affect its future developmental plans. An 85\% cut may force India to lower its emissions to $<0.2 \mathrm{t} \cdot \mathrm{CO}_{2} \mathrm{e}$.

\subsubsection{India's energy and electricity demand scenario}

With only $0.4 \%$ of the globe's proven reserves of crude, India accounts for $2.8 \%$ of the world's total oil consumption. To fuel a booming transport sector, $70 \%$ of its oil requirements are imported at huge costs to the exchequer. Large imports of LNG too are required to supplement indigenous production. As the numbers of vehicles in India grow, oil and LNG imports will follow suit. Food items and essential commodities became pricier when oil prices peaked in 2008. Unprecedented high inflation levels, attributed by policy makers to oil market economics and India's growth story, have stretched the budgets of many families. 
Global petroleum price increases will pose concerns for India as she copes with her apparently insatiable demand for crude oil. Another facet of India's energy concerns is that growing numbers of new vehicle buyers are opting for compact electric vehicles (EV) which can be re-charged easily using a domestic electrical socket, and several manufacturers are catering to this new demand. The road use policy currently requires no license, registration, or taxes for such EV. With improved affordability, many Indians are buying air-conditioners and electrical appliances that were, not long ago, considered items of luxury. As the numbers of EV, TV-sets and washing machines in use grow, enormous demands are placed on India's already scarce power supply. Several Indian cities experience daily power outages, inconveniencing its citizens and many small and medium business enterprises.

\subsubsection{National electricity policy (NEP)}

India aims to augment its power generation capacity by $100 \mathrm{GW}$ during the $10^{\text {th }}$ (2002-07) and $11^{\text {th }}$ Plan periods (2007-12), besides improving the annual per capita energy availability to $1 \mathrm{MWh}$ [1]. In 2005, a national program was launched to electrify all villages and make electricity accessible to all households by 2012, through a mix of grid-connected, standalone systems and isolated lighting technologies. The NEP also aims to overcome chronic shortages in meeting peak electricity demand, besides ensuring efficient and reliable supply of power of specified standards at affordable prices.

\subsubsection{The way forward with renewable energy}

India has a large under-exploited potential for hydro-power generation, confined to certain geographical locations. She currently produces limited amounts of atomic energy for civilian use, due to her foreign policy leanings towards nuclear fuel exporting nations. Although the recent (and controversial) Indo-US nuclear agreement assures fuel supplies and reactor equipment, India has far to go before nuclear power overtakes fossil fuel power generation. To eradicate chronic electricity shortages, and compete in a carbon-sensitive global economy, India must go in for decentralized renewable energy (RE) technologies. Decentralization is essential for reducing transmission and distribution (T\&D) losses in the existing grid networks. In the present centralized set-up, maintenance shut-downs, grid failures, and strikes impact vast areas of densely-populated India. Decentralization would also promote power production using locally available resources; such as biomass and wind [4].

\subsection{Purpose of the study}

Several policies have been formulated by successive governments that offer fiscal incentives to the users of RE. Over 25 years ago, India launched a national program for the assessment of her wind resources to promote WEG. As one outcome, 233 sites with an annual average wind power density (WPD) $>200 \mathrm{~W} / \mathrm{m}^{2}$ have been identified thus far. Many such sites are in the industrialized states of Tamil Nadu (TN), Maharashtra (MH) and Gujarat (GJ). Estimates suggest a gross potential of $48.6 \mathrm{GW}$ of wind power for the entire country, with TN (5.5 GW), $\mathrm{MH}$ (4.6 GW), and GJ (10.6 GW) among other front-runners in this category [5].

There are many functional, and many more upcoming, WEG projects within India. This study attempts to assess (a) whether the current policies that aggressively promote WEG have yielded any significant addition to the overall power generation scenario, and (b) whether there has been any alleviation in chronic electricity shortages as a consequence. This study is limited to ascertaining the policies for, and status of, WEG in the states of TN, MH, and GJ, which have witnessed a boom in wind energy installations in the past few years. When 
juxtaposed with other concurrent policies relating to power production and supply, it is hoped that a more holistic view of WEG within India would emerge.

\subsection{Methodology of the study}

Data has been sourced from the web-sites of central and state agencies involved in WEG, which in most cases tended to be in fair consonance. Reports on electricity shortages, energy policy and WEG in the print media (e.g. national-level newspapers), and reports by reputed non-governmental agencies, have been utilized. Data obtained from web-sites is referenced by mentioning the date of access (DoA).

\section{State-wise electricity scenario and wind energy generation}

\subsection{In Tamil Nadu}

Located in peninsular India, TN experiences both the monsoons: south-west and north-east. The state's annual per capita power consumption is nearly 1 MWh. Its major WEG sites are near the Western Ghats and (to a small extent) along its coastline. From 1986-93, 120 WEG units totaling 19.4 MW were installed. By 2009, the total installed capacity (IC) for WEG was $4.288 \mathrm{GW}$, against a gross power generation capacity of $10.214 \mathrm{GW}[5,6]$.

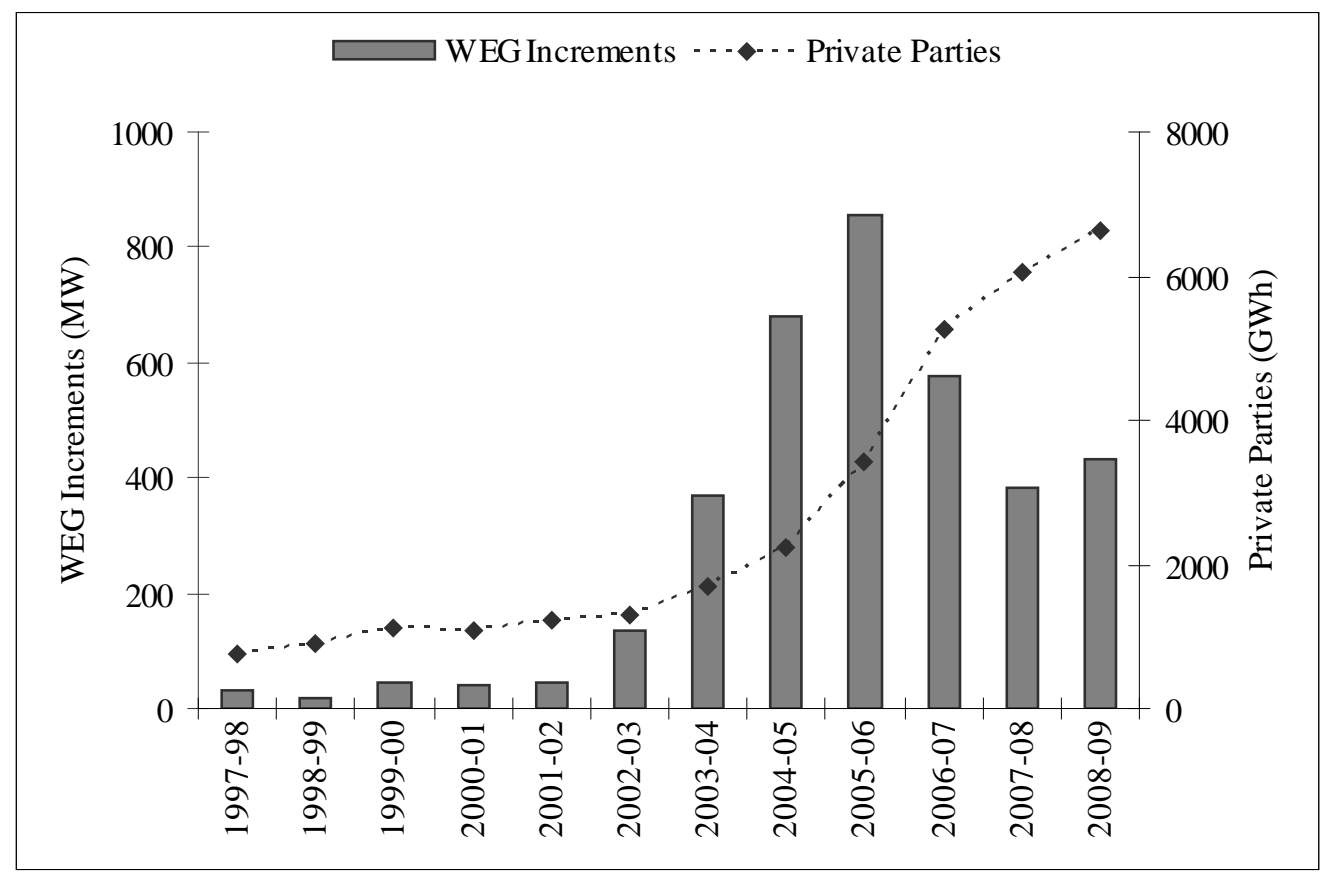

Fig. 1. Increments to WEG, and contributions to WEG by privately-owned units, in Tamil Nadu [6].

The state inducts independent power producers (IPP) into its WEG program. The state electricity board (TNEB) charges the IPP a fee of Rs. 2.575mn (million) per MW installed, plus more if creation and maintenance of T\&D facilities by the TNEB is opted for. The IPP have to execute a 15-year power purchase agreement with the TNEB. In 1995-96, the IPP were paid Rs.2.25 per kWh by the state, with a 5\% annual increment. Currently, Rs.3.39 is offered based on the recommendations of the state electricity regulatory commission (SERC), in view of the rising capital, interest and maintenance costs. Contributions to WEG from private parties are shown in Fig. 1. In recent years, there is a decline in the augmentation of TN's WEG capacity (see Fig. 1). Saturation of existing sites may be one reason. Investors have also shifted to MH and GJ which offer competitive prices (refer Table 1). 
Table 1. State-wise wind electricity generation policies [7].

\begin{tabular}{llll}
\hline \multicolumn{1}{c}{ Policy Item } & Tamil Nadu & Maharashtra & Gujarat \\
\hline (a) Captive use of WEG & Allowed & Allowed & Allowed \\
(b) Wheeling charge rate & $5 \%$ & $2 \%+5 \%$ for T\&D losses & $4 \%$ \\
(c) Buy-back (Rs./kWh) & 3.39 (fixed) & Levelized tariff (refer [7]) & 3.56 (fixed) \\
(d) Third party sale & Allowed & Allowed & Allowed \\
(e) Other incentives & None & Off-take facilities, & Excise exemption \\
& & road, loans & \\
\hline
\end{tabular}

\subsubsection{Electricity crisis in Tamil Nadu}

Since late-2007, serious electricity shortages plague TN. Over the past decade, the state has pro-actively sanctioned investments into its information technology, automobile and manufacturing sectors, all clustered around its capital city Chennai. Spurred by such policy, demand for electricity has grown every year. It is reported that while the peak demand touched $9.5 \mathrm{GW}$ on some days, the generation was only $6.7 \mathrm{GW}$ [8]. According to industry experts the electricity crisis would continue for another 3-4 years [9]. To tide over shortages, the TNEB formulated policy changes to curtail consumption. A $40 \%$ cut imposed in the permitted power consumption by industries effectively crippled operations in many automobile ancillaries, farming and fishing industries all over TN. Textile industries are reportedly worst-hit, with machines requiring a 2-2.5 hour interval after restart to attain their full capacity, each time they are tripped by the erratic power supply. Automobile manufacturers are reported to have diverted their orders elsewhere, instead of sourcing products from within the state [10].

\subsubsection{Status of wind electricity generation in Tamil Nadu}

Plots of IC and "workable" (available) capacity (WC) for WEG on the $15^{\text {th }}$ day of each month are shown in Fig. 2, based on daily TNEB reports [11].

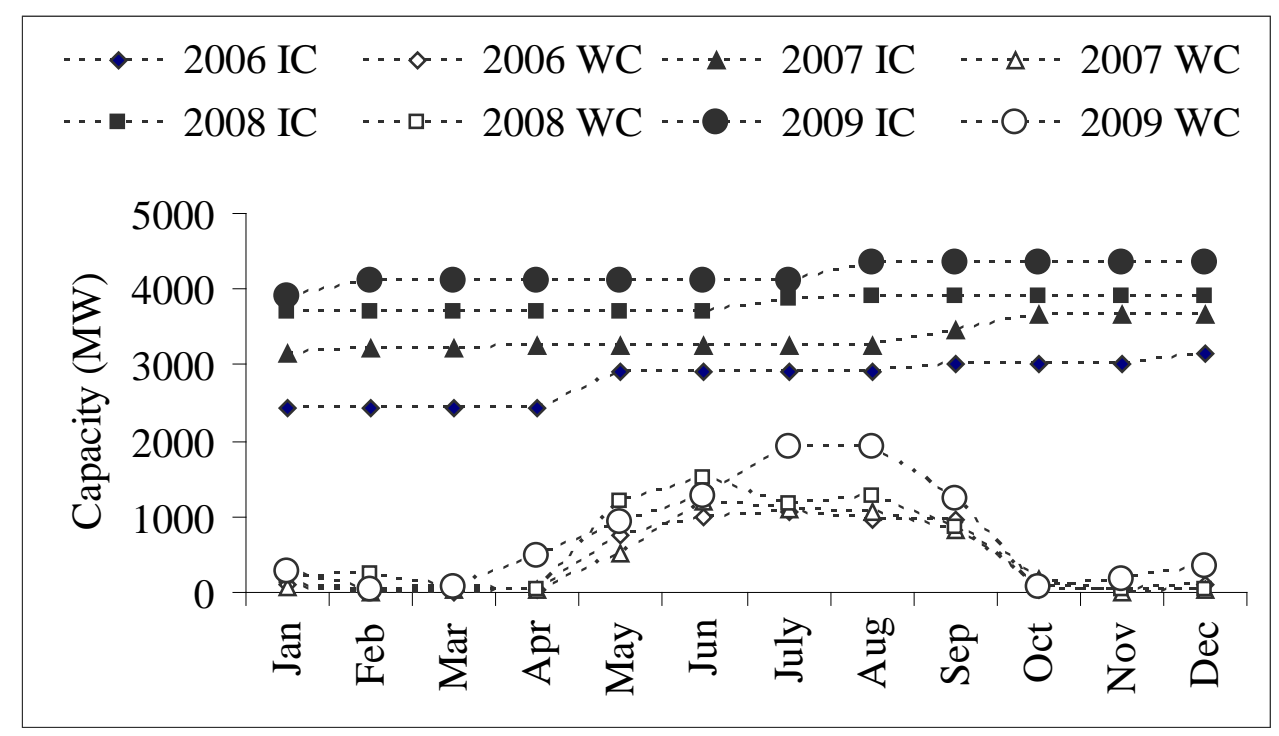

Fig. 2. WEG in Tamil Nadu: Monthly variations in installed and workable capacities [11].

Only one day's data was chosen as being representative for an entire month because several electronic reports were missing or were corrupted. Besides, the number of figures and data 
being presented here had to be limited. The following can be observed from Fig. 2: (a) From Jan. 2006 to Dec. 2009, there has been an 80\% increase in the IC for WEG, and (b) WEG is significantly more during May to Sep., compared to the other months of each year. The MaySep. averaged generation was 950 MW (in 2006), 942 MW (2007), 1204 MW (2008), and $1451 \mathrm{MW}$ (in 2009). When the above seasonal averages are normalized by the corresponding IC for WEG, the figures reveal that the capacity utilization factor (CUF) was 0.33 (in 2006), 0.29 (2007), 0.32 (2008), and 0.36 (in 2009). Although the IC has substantially increased during 2006-09, the available capacity has remained steady at roughly 33\% of the IC, and that too during these five months in a year. During the remaining months, the CUF of the WEG units are extremely small numbers.

One reason for the low utilization could be the wind patterns: if monsoons fail during a particular year, it is the wind conditions that are blamed. But WEG in TN has suffered not just because the winds play truant. Even with favorable winds, only 5.25bn (billion) kWh could be generated, as against a possible $8.25 \mathrm{bn} \mathrm{kWh}$. It is claimed that due to inadequate evacuation facilities for wind electricity, losses to the tune of 0.8-0.9 GW arise, and that the TNEB prefers to shed load. In southern TN, out of the IC of $2.21 \mathrm{GW}$ for WEG, only $1.2 \mathrm{GW}$ are generated [12]. Due to the poor off-take policies, wind power producers in TN claim they have lost close to Rs.9bn, and Rs.45bn worth of their investments lie idle. The TNEB counters that the IPP install a unit every six months, but it takes nearly 12 months to build new transmission lines. Connecting remote wind farms to the grid is not easy when the lines have to pass over private lands.

\subsection{In Maharashtra and Gujarat}

\subsubsection{Maharashtra}

Within $\mathrm{MH}$, thermal and hydro-power plants having a total IC of almost $10 \mathrm{GW}$ are owned and operated by the state. Nearly $1.8 \mathrm{GW}$ of power is produced by IPP. During the 1990s, the state was embroiled in a dispute over the Enron-Dabhol power project which was supposed to provide nearly $2 \mathrm{GW}$ of gas-based power. That project did not take-off as expected. More recently, $\mathrm{MH}$ has faced acute shortages to the extent of 5-6 GW in meeting peak demands. The state has generally had a poor record of managing T\&D losses in its electricity networks.

In an effort to showcase the viability of WEG, the state has installed demonstration projects totaling 11.09 MW. These and other favorable policies of the state towards WEG have attracted investments close to Rs.105bn. From a mere $190 \mathrm{MW}$ in 2000-01, nearly $2.1 \mathrm{GW}$ of wind power projects had been set up by 2010 [13]. Many older units of $250 \mathrm{~kW}$ operating at $30 \mathrm{~m}$ above ground $(250 \mathrm{~kW}, 30 \mathrm{~m})$ were replaced with $1 \mathrm{MW}, 50 \mathrm{~m}$ units to exploit the higher WPD and realize lower investment costs per MW. Yearly increments to WEG capacity have been declining, though. The state added $545 \mathrm{MW}$ in 2005-06, $485 \mathrm{MW}$ in 2006-07, and $268 \mathrm{MW}$ in 2007-08. It has targeted to add $600 \mathrm{MW}$ to its WEG capacity each year from 2008-09, to achieve a cumulative capacity > 4.1 GW by 2012. A 1 GW wind farm, the largest of its kind, is currently under erection in the state.

To promote wind farm development, the govt. allows the use of state-owned wastelands which are leased out to private developers for 30 years at market rates. For other incentives offered, refer Table 1. But all is not well with wind power projects in $\mathrm{MH}$, as revealed in a status paper which claims that though $1.76 \mathrm{GW}$ of WEG units were installed by 2008, their combined annual generation was only $1.8 \mathrm{bn} \mathrm{kWh}$ [14]. CUF increased from a mere $8.6 \%$ in $2000-01$ to $11.7 \%$ in $2007-08$, after touching $19.2 \%$ in $2003-04$. That article also points out that investors are not interested in WEG and have merely invested in these facilities to gain 
from the accelerated depreciation and tax benefits offered by the govt. There have been other independent reports of developers clashing with locals, over issues of land acquisition.

\subsubsection{Gujarat}

Thermal and hydro-power, are the mainstays for electricity generation in this state. The IC for power generation is $9.6 \mathrm{GW}$, with nearly $1.5 \mathrm{GW}$ in projects under development. IPP provide close to $3.7 \mathrm{GW}$. The demand for power is expected to grow to $14 \mathrm{GW}$ by 2011-12. This was one state that was comfortably placed as regards electricity supply [15], but the situation has changed due to coal and LNG shortages [16]. Endowed with a long coastline, GJ receives the south-west monsoon winds almost head-on. The state set up its first WEG demo unit in 1986. Later, more units were installed totaling 16.3 MW. In 1993 the state govt. declared an incentive program inviting private-sector participation, and from 1993-98 investments in WEG boosted the IC to $150 \mathrm{MW}$. In 2002, the govt. revealed a new policy, and WEG capacity grew by $220 \mathrm{MW}$ till Nov. 2006, reaching $570 \mathrm{MW}$ by Mar. 2007. It is reported that these units generated close to 455mn kWh in 2006-07. In 2007-08, new capacity additions of $616 \mathrm{MW}$ were made and the total IC for WEG rose to $1.2 \mathrm{GW}$ [17]. For the $11^{\text {th }}$ Plan period, the state proposes to add nearly $4 \mathrm{GW}$ of capacity to WEG. The Indian Railways plans to invest Rs.700mn for a 10.5 MW wind farm in the state. Power so generated is proposed to be wheeled away for railway electric traction - an unlikely prospect. Although the state now ranks next only to TN and MH in terms of the IC for WEG, the CUF of the units in operation are a measly $8 \%$ [18].

\section{Discussion}

On one hand, it may be said that the rapid growth in India's WEG sector has been facilitated by several incentive-laden policies which make investments into WEG very attractive for investors. On the other hand, it may be said that when incentives are geared to attract investments rather than improve the utilization of existing WEG units, such projects could become conduits to launder money. A study has alleged a nexus between monopolistic wind turbine makers and cash-rich investors, to avail of the huge (80\%) depreciation benefits offered to WEG units during their first year of operation besides tax holidays and a slew of other duty cuts [14]. If this were the case, investors would care less whether the installations have poor CUF, or whether they remain idle. The same report also claims that business dealings in wind energy are opaque, and that the true costs of capital are unclear. Instead of reducing, based on economies of scale, costs of WEG units have reportedly gone up from Rs.40mn to Rs.60mn per MW over the years. Agreements exist to sell wind electricity to grids, third parties, or use for own consumption. Very few records are available in the public domain on how much wind power is actually delivered to the grid. Rules prescribe a certain percentage of wind electricity produced to be supplied to a grid, but enforcement is lax and the miniscule quotas are usually exhausted by other sources of green energy. The SERCs must make daily reporting of WEG mandatory for all IPP and state electricity boards.

Land acquisition for wind farming has affected many vulnerable farmers reeling under repeated crop failures and loans from usurers, and families coping with farmer suicides. There are reports of coercive methods being adopted for land grabbing by middle-men representing wind farm developers [19]. Villagers are promised monetary compensation and other benefits in return, but most promises never materialize and the sellers find their position a lot worse afterwards. Govt. policies must insure that land, instead of being sold, is leased out to wind farm companies and fair market rents are paid to the lessors. Large-scale removal of trees and forest cover to erect wind farms affects the livelihood of villagers dependent on 
these natural resources. They languish in poverty and darkness with noisy wind turbines for company, and whatever little power the units generate is wheeled away to the cities.

Besides rapid industrialization, other factors contribute significantly to the India's widening electricity deficit. Many political parties in India, at the centre and in the states, have used provision of free electricity for farming as a poll plank. Income from agriculture qualifies for federal income-tax relief too. Such policies have led to write-offs of huge debts owed by farmers to the state electricity boards. The provision of free power for farming has an adverse cascading effect. During droughts, farmers use electricity to pump out ground-water for irrigation. These pumps run endlessly, deplete the ground-water table and increase soil salinity. With power available for free, shortages notwithstanding, farmers neither conserve the precious ground-water nor the electricity. Illegal connections, faulty meters, lax monitoring, and T\&D losses allow for gross under-recoveries of electricity consumed. Revenue losses stifle genuine investments in the power sector and promote an indifference towards electricity conservation. In many instances, power is simply wasted when consumers deliberately choose not to switch off. Extravagant lighting for political gatherings, cine-artiste shows, mega-bucks night-time cricket tournaments, etc. has become a routine affair.

Instead of viewing WEG as a panacea for their ailing power sector, Governments could frame policies to award discounts on electricity bills to consumers who (a) reduce their electricity usage, and (b) maintain it thereafter within a certain threshold. Such incentives can be offered with ease since billing is nowadays computerized, allowing for the processing of long-term electricity usage patterns. Governments must implement policies that offer cash discounts for the purchase of CFLs and LEDs for domestic lighting. Such products continue to be prohibitively expensive for many, who opt instead for inefficient incandescent bulbs.

\section{Conclusions}

Policies for, and status of, wind electricity generation (WEG) in three major states of India are explored. The policies of the various state governments to promote WEG have led to a spree of investments in this sector. But the spectacular increase witnessed in the recent past in the installed capacity for WEG has not necessarily translated into a mitigation of electricity shortages in these states. Existing units face problems relating to under-evacuation and grid integration, and operate with poor capacity utilization factors. Very little credible information exists in the public domain on the actual power delivered by wind farms to the electricity grids, the true costs incurred, and the incomes generated. The liberal incentives offered are possibly being misused by investors for pecuniary benefit. In order to change this situation for the better, governments must revise their relevant wind energy policies to remove loopholes. Instead of promoting a headlong rush into WEG projects with further sops, govt. policies must reward generation and optimum utilization of the existing units. One way would be to increase and strictly regulate the percentage of wind power supplied to the grids by the IPP, and not to yield to demands for more concessions from the wind energy lobby. Novel applications of wind electricity to suit Indian requirements must be thought of. Instead of MW-scale grid-connected units, smaller-scale solar-assisted decentralized WEG units that can be installed at community levels must be promoted. Electricity so produced can be used to provide metered back-up for residential use, street lighting, or water supply. The use of wind electricity for decentralized applications such as battery-charging, water treatment and purification, and production of compressed air must be explored. WEG must be matched properly with demands of an appropriate kind, in order to maximize the benefits. 


\section{References}

[1] Ministry of Power, Govt. of India, (DoA: Oct. 20, 2010) at www.powermin.nic.in/indian_electricity_scenario/introduction.htm, www.powermin.nic.in/whats_new/national_electricity_policy.htm.

[2] Planning Commission, Govt. of India, (DoA: Oct. 20, 2010) at www.planningcommission.gov.in/plans/planrel/fiveyr/10th/volume2/v2_ch7_3.pdf, www.planningcommission.gov.in/plans/planrel/fiveyr/11th/11_v3/11th_vol3.pdf, www.planningcommission.gov.in/reports/genrep/rep_intengy.pdf.

[3] R. Ramachandran, Climate change and the Indian stand, The Hindu, Jul. 28, 2009.

[4] P. Purohit, and A. Michaelowa, Potential of wind power projects under the Clean Development Mechanism in India, Carbon Balance and Management, 2(8) (doi: 10.1186/1750-0680-2-8).

[5] Centre for Wind Energy Technology, (DoA: Oct. 21, 2010) at www.cwet.tn.nic.in.

[6] Tamil Nadu Electricity Board, (DoA: Oct. 21, 2010) at www.tneb.in.

[7] Wind Power India, (DoA: Oct. 20, 2010) at www.windpowerindia.com/govtinc.html.

[8] V. P. Abhir, South India reeling under a power crisis, IBN-Live, Nov. 26, 2008.

[9] R. Ashok, Power crisis to continue for 3-4 years: CII study, Business Line, Sep. 27, 2008.

[10] Power Crisis has hit farming, industry hard, The Hindu, Sep. 01, 2008.

[11]TNEB Reports, Daily online reports, at http://tnebldc.org/tnercreports.htm.

[12] M. Allirajan, Gone with the wind, Business World, Feb. 01, 2008.

[13] Maharashtra Energy Development Authority, (DoA: Oct. 26, 2010) at http://www.mahaurja.com.

[14]N. Jamwal, and S. Lakhanpal, Fanning an alternative, Down To Earth, Centre for Science and Environment, New Delhi, 17(6), 2008.

[15] V. Pandit, Gujarat: Energizing the nation with power, natural gas, Business Line, Oct. 09, 2007.

[16]C. H. Hansen, Bottom-up electricity reform using industrial captive generation: A case study of Gujarat, India, Oxford Institute for Energy Studies, Mar. 2008, pp. 9.

[17] Gujarat Energy Development Agency, (DoA: Oct. 26, 2010) at www.geda.org.in (for wind related articles refer to www.geda.org.in/wind/wind_power.htm).

[18] Govt. fumbles for 'power' as wind energy is left untapped, Express News Service, Sep. 16, 2008.

[19]M. Suchitra, Windmills on tribal land, Down to Earth, Centre for Science and Environment, New Delhi, 19(7), 2010. 